\title{
Inverse Problem of Air Filtration of Nanoparticles: Optimal Quality Factors of Fibrous Filters
}

\author{
Dahua Shou, ${ }^{1,2}$ Jintu Fan, ${ }^{1}$ Lin Ye, ${ }^{2}$ Heng Zhang, ${ }^{3}$ Xiaoming Qian, ${ }^{3}$ and Zhong Zhang ${ }^{4}$ \\ ${ }^{1}$ Department of Fiber Science \& Apparel Design, College of Human Ecology, Cornell University, Ithaca, NY 14853, USA \\ ${ }^{2}$ Centre for Advanced Materials Technology, School of Aerospace, Mechanical and Mechatronic Engineering, The University of Sydney, \\ NSW 2006, Australia \\ ${ }^{3}$ School of Textile, Tianjin Polytechnic University, Tianjin 300160, China \\ ${ }^{4}$ National Center for Nanoscience and Technology, Beijing 100190, China
}

Correspondence should be addressed to Dahua Shou; dhshou@gmail.com

Received 20 August 2015; Accepted 1 October 2015

Academic Editor: David Cornu

Copyright (C) 2015 Dahua Shou et al. This is an open access article distributed under the Creative Commons Attribution License, which permits unrestricted use, distribution, and reproduction in any medium, provided the original work is properly cited.

Application of nanofibers has become an emerging approach to enhance filtration efficiency, but questions arise about the decrease in Quality factor $(\mathrm{QF})$ for certain particles due to the rapidly increasing pressure drop. In this paper, we theoretically investigate the QF of dual-layer filters for filtration of monodisperse and polydisperse nanoparticles. The inverse problem of air filtration, as defined in this work, consists in determining the optimal construction of the two-layer fibrous filter with the maximum QF. In comparison to a single-layer substrate, improved QF values for dual-layer filters are found when a second layer with proper structural parameters is added. The influences of solidity, fiber diameter, filter thickness, face velocity, and particle size on the optimization of QF are studied. The maximum QF values for realistic polydisperse particles with a lognormal size distribution are also found. Furthermore, we propose a modified QF (MQF) accounting for the effects of energy cost and flow velocity, which are significant in certain operations. The optimal MQF of the dual-layer filter is found to be over twice that of the first layer. This work provides a quick tool for designing and optimizing fibrous structures with better performance for the air filtration of specific nanoparticles.

\section{Introduction}

The capture of nanoparticles from gas streams is critical in many fields, including protective clothing, respirators, air cabin filters, indoor air purifiers, and industrial air purification systems [1]. The filtration performance of fibrous filters is typically measured by the quality factor (QF), also known as the figure of merit, which is the ratio of the penetration rate of particles $P$ to the pressure drop across the filter $\Delta p$ [2],

$$
\mathrm{QF}=\frac{-\ln (P)}{\Delta p} .
$$

Here, $P$ is equal to $1-E$, where $E$ is the total filtration efficiency of the filter. A dense and thick filter is often more efficient in particle filtration and has a higher flow resistance or $\Delta p$, whereas a dilute and thin filter is more permeable and has a higher $P$ for particles. Hence, improvement of filter efficiency may compensate for an increase in the pressure drop. In this study, we focus on the evaluation of the filtration performance of fibrous filters, aiming to find the maximum QF with an optimal interplay between $P$ and $\Delta p$.

The design of fibrous filters is based on the fact that filtration behavior is highly dependent on filter structure, particle size, and flow pattern. In general, filtration mechanisms that rely on mechanical capture include interception, diffusion, and inertial impaction [2]. A minimum at the most penetrating particle size (MPPS) usually exists between 0.1 and $0.5 \mu \mathrm{m}$ due to the combined action of these filtration mechanisms, which have different sensitivities to particle size [3]. In comparison to coarse fibers, the use of fine fibers as a filter engenders a smaller MPPS and higher filtration efficiency. However, the pressure drop of filters composed of finer fibers becomes much greater as it decreases with the square of fiber radius, even for extremely fine nanofibers 
TABLE 1: Improvement of filtration performance of fibrous filters by morphology modification.

\begin{tabular}{|c|c|c|c|}
\hline Type & Improved performance & Possible reasons & Reference \\
\hline Adding beaded nanofibers & $\begin{array}{l}\text { Exhibited better filtration } \\
\text { performance for aerosol particles } \\
\text { ranging from } 20 \text { to } 300 \mathrm{~nm} \text { than } \\
\text { nanofibers and } \\
\text { particle/nanofiber composites }\end{array}$ & $\begin{array}{l}\text { Increased void volume and } \\
\text { aspect ratio }\end{array}$ & {$[20]$} \\
\hline $\begin{array}{l}\text { Coating multisize } \\
\text { nanoparticles on } \\
\text { electrospun nanofibers }\end{array}$ & $\begin{array}{l}\text { Complimentary filtration } \\
\text { efficiency }(99.989 \%) \text { and pressure } \\
\text { drop }(117 \mathrm{~Pa}) \text { for } \\
300-500 \mathrm{~nm} \mathrm{NaCl} \text { aerosol } \\
\text { particles }\end{array}$ & $\begin{array}{l}\text { Rough surface and noncircular } \\
\text { cross section of fibers }\end{array}$ & {$[21]$} \\
\hline $\begin{array}{l}\text { Depositing a low amount of } \\
\text { carbon nanotube }(\mathrm{CNT}) \\
\text { films }\end{array}$ & $\begin{array}{l}\text { Filtration efficiency }>99 \% \text { in all } \\
\text { cases and meeting the guidelines } \\
\text { of HEPA filters; higher pressure } \\
\text { drops but better QFs than the } \\
\text { substrate }\end{array}$ & $\begin{array}{l}\text { A broad micropore size } \\
\text { distribution and a few mesopores } \\
\text { between CNTs }\end{array}$ & {$[22]$} \\
\hline $\begin{array}{l}\text { In situ growth of brush-like } \\
\text { CNTs on quartz fibers }\end{array}$ & $\begin{array}{l}\text { Pressure drop moderately } \\
\text { enhanced, but QF improved } \\
\text { fairly well }\end{array}$ & $\begin{array}{l}\text { Slightly reduced pore sizes, much } \\
\text { larger specific surface area }\end{array}$ & {$[23,24]$} \\
\hline
\end{tabular}

with a slip flow condition $[4,5]$. Moreover, a random and inhomogeneous fiber arrangement makes the actual filter more permeable but less efficient in filtration than ordered fiber arrays [6-8]. Therefore, an inhomogeneity factor has been introduced to fit the order-based model to experimental results [9]. The filtration efficiency of filters varies with the face velocity and the MPPS shifts accordingly as well [10].

Utilization of nanofibers has become an emerging approach to enhance air filtration efficiency [11-16]. A composite of microfibers and nanofibers has been found to significantly improve the capture efficiency and QF for MPPS, whereas a single layer of nanofibers only leads to an increase in QF for very large particles [3, 17]. The QF for a duallayer filter manufactured by the melt-blown technique is much higher than that of the microfiber substrate alone, as the increase in filtration efficiency is not overpaid with an excessive pressure drop [3]. Filtration tests have also indicated that a microfiber substrate layered by a single nanofiber mat of $0.15 \mu \mathrm{m}$ diameter has a higher QF than conventional fiberglass filters for particles larger than $0.5 \mu \mathrm{m}$ [18]. The QF for nanoparticles is observed to decline with a decrease in nanofiber diameter whereas the QF for larger particles increases with increasing nanofiber diameter [18]. It is believed that, for nanoparticles, the pressure drop increases more rapidly than the filtration efficiency due to diffusion; for large particles, the filtration efficiency predominated by interception and inertial impaction increases more rapidly than the pressure drop [17]. For a dual-layer filter with mean fiber diameters $14.7 \mu \mathrm{m}$ and $0.208 \mu \mathrm{m}$, respectively, filtration performance has been found to decrease with face velocity [10]. This phenomenon is caused by the much lower likelihood for particles to collide on fibers through diffusion filtration at a smaller face velocity. Enhanced QF has also been observed in a thick layer alone in comparison to multiple thin layers of electrospun nanofibers, as multilayer filters have greater uniformity and smaller fiber sizes [19].
The QF of fibrous filters is also improved by modification of the morphology, including adding beaded nanofibers [20], coating multisize nanoparticles on electrospun nanofibers [21], depositing a low amount of carbon nanotube (CNT) films [22], and in situ growth of brush-like CNTs on quartz fibers $[23,24]$. The results of increased QF and the possible explanations are summarized in Table 1.

The filtration quality of a clean filter is not sensitive to the deposition of particles in a short period, but it is strongly affected by particle loading over a long term [1]. With solid particles clogging to form a dust cake in the filter, flow resistance increases exponentially and penetration decreases at a given flow rate [1]. It is interesting to see that the deposited particles are more efficient in filtration than the fibers, as dendrite aggregate is formed with a high specific surface. To take into account continuous and unsteady loading of particles, a more realistic criterion of filtration performance, namely, the filter utility factor (FUF), has been proposed [25]. A cost-effective filter with higher dust-holding capacity has also been designed based on graded fibrous media [25]. The arrangement of a microfiber substrate in front of a nanofiber layer also gives a filter high filtration efficiency in the initial stage and a low increase in drop during continuous loading [26].

From the above discussion we find that there is less concern to design and optimize the fibrous filters to maximize the QF for nanoparticles. Layering of nanofibers onto a microfiber substrate leads to an increased QF over a certain range of particle size, but it may decrease the QF for the other particles. In practical filtration processes, the aim is often to capture particles of a specific size, such as the MPPS, the mean particle size, or the highest proportion particle size. Hence, as an inverse problem, in addition to avoiding any decrease in QF, we attempt in this paper to determine the optimal structural parameters that lead to the maximum QF for these target nanoparticles based on a dual-layer fibrous 


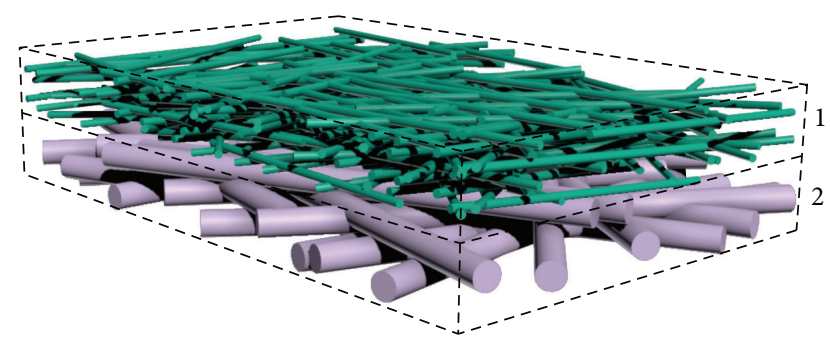

FIGURE 1: Illustration of a dual-layer fibrous filter composed of two layers of fibers with the first layer fixed while the second layer varied with different solidity, fiber diameter, and thickness.

filter as illustrated in Figure 1. Here, the first layer is fixed while the second layer varies with different solidity, fiber diameter, and thickness. Furthermore, QF has been found not to be an energy-cost-based index [1]. To this end, we explore the filtration performance of dual-layer fibrous filters on the basis of a modified QF (MQF), by concerning energy cost and flow velocity.

\section{Analysis of Theoretical Expressions}

This study concerns the filtration of fine particles in clean filters. The assumptions are made that particle clogging is negligible and no particle rebounds from the fiber.

Filter efficiency $E$ is derived on the basis of single fiber efficiency (SFE), making a mass balance for particles in a given filter and integrating from the filter face to the exit [2],

$$
E=1-\exp \left[\frac{-4 c E_{t} h}{\pi(1-c) d_{f}}\right]
$$

where $c$ is solidity, $d_{f}$ is fiber diameter, and $E_{t}$ is total SFE, which is calculated based on the assumption that different filtration mechanisms act independently [2]. $E_{t}$ is generally expressed as follows:

$$
E_{t}=1-\left(1-E_{D}\right)\left(1-E_{R}\right)\left(1-E_{I}\right),
$$

where $E_{D}, E_{R}$, and $E_{I}$ are SFEs caused by diffusion, interception, and inertial impaction, respectively. By taking into account the aerodynamic slip on the SFE based on diffusion, the following expression is given for $E_{D}$ [27]:

$$
E_{D}=2.27 \mathrm{Ku}^{-1 / 3} \mathrm{Pe}^{-2 / 3}\left(1+0.62 \mathrm{KnKu}^{-1 / 3} \mathrm{Pe}^{1 / 3}\right),
$$

where $\mathrm{Ku}$ is the Kuwabara hydrodynamic factor, which is equal to $\mathrm{Ku}=-\ln (c) / 2-3 / 4+c-c^{2}$ and $\mathrm{Kn}$ is the Knudsen number given by $\mathrm{Kn}=2 \lambda / d_{f}$. Here, $\lambda$ is the mean free path of the gas molecules and the Peclet number Pe is given as $\mathrm{Pe}=d_{f} U / D$, where $U$ is the face velocity and $D$ is the diffusion coefficient of particles. $D$ is widely evaluated by the Stokes-Einstein equation [1]; namely,

$$
D=\frac{k T C}{3 \pi \mu},
$$

where $T$ is the temperature, $k$ is Boltzmann's constant, $C$ is the slip factor, and $\mu$ is the gas viscosity. The expression of $C$ is given by

$$
C=1+\frac{\lambda}{d_{p}}\left[2.33+0.966 \exp (-0.4985) \frac{d_{p}}{\lambda}\right] .
$$

The SFE due to interception is given as follows [2]:

$$
\begin{aligned}
& E_{R} \\
& =\frac{\left(1+N_{R}\right)^{-1}-\left(1+N_{R}\right)+2(1+1.996 \mathrm{Kn})\left(1+N_{R}\right) \ln \left(1+N_{R}\right)}{2[-0.75-0.5 \ln (c)]+1.996 \mathrm{Kn}[-0.5-\ln (c)]},
\end{aligned}
$$

where $N_{R}$ is the ratio of $d_{p}$ to $d_{f}$. The model is accurate when $N_{R}<0.2$. The SFE caused by the inertial effect is calculated as the following form [2]:

$$
E_{I}=\frac{J S t}{2 \mathrm{Ku}^{2}}
$$

where St is the Stokes number, namely, St $=d_{p}^{2} \rho C U / 18 d_{f} \mu$, and $J$ is equal to $J=\left(29.6-28 c^{0.62}\right) N_{R}^{2}-27.5 N_{R}^{2.8}$ for $N_{R}<0.4$ and $J=2$ when $N_{R}>0.4$.

The pressure drop for nonwoven-like filters composed of randomly layered fibers is calculated as follows [5]:

$$
\Delta p=\frac{16 \mu c U h(1+2 \mathrm{Kn})}{d_{f}^{2}\left\{-0.6 \ln (c)-0.74+c-0.25 c^{2}+2 \operatorname{Kn}\left[-0.6 \ln (c)-0.14+0.25 c^{2}\right]\right\}} .
$$

In Figure 2, we examine the effects of filtration mechanisms on the QF of a single-layer fibrous filter. The QFs for diffusion-only, interception-only, inertial impaction-only, and the combined filtration mechanisms are compared at $U=0.1 \mathrm{~m} / \mathrm{s}, d_{f}=1 \mu \mathrm{m}, c=0.05$, and $h=1 \mathrm{~mm}$. For nanoparticles (below $0.1 \mu \mathrm{m}$ ), the QF based on the combined filtration mechanisms decreases with an increase in particle size, approaching the diffusion-only QF. For micro and submicro particles (above $0.1 \mu \mathrm{m}$ ), the total QF based on the combined filtration mechanisms increases with an increase in particle size, which is consistent with the interception-only and inertial impaction-only cases. We find that diffusion filtration is dominant for nanoparticles and submicro particles $(<1 \mu \mathrm{m})$ whereas interception and inertial impaction become more critical to the $\mathrm{QF}$ in the range of large particles $(>3 \mu \mathrm{m})$. It is expected that very small particles are captured through random collision with fibers due to Brownian motion. Larger particles are intercepted by fibers in 


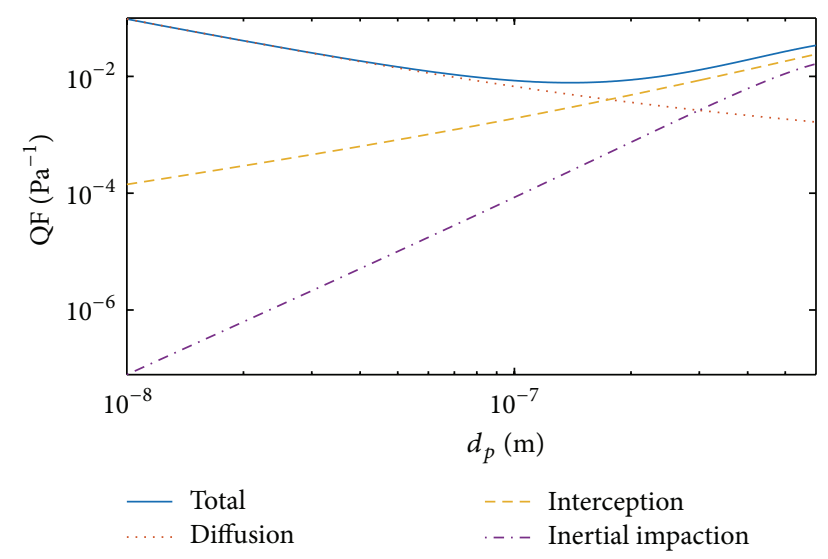

FIGURE 2: Effects of filtration mechanisms on the QF of a singlelayer filter, including diffusion-only, interception-only, inertial impaction-only, and the combined filtration mechanisms $(U=$ $0.1 \mathrm{~m} / \mathrm{s}, d_{f}=1 \mu \mathrm{m}, c=0.05$, and $h=1 \mathrm{~mm}$ ).

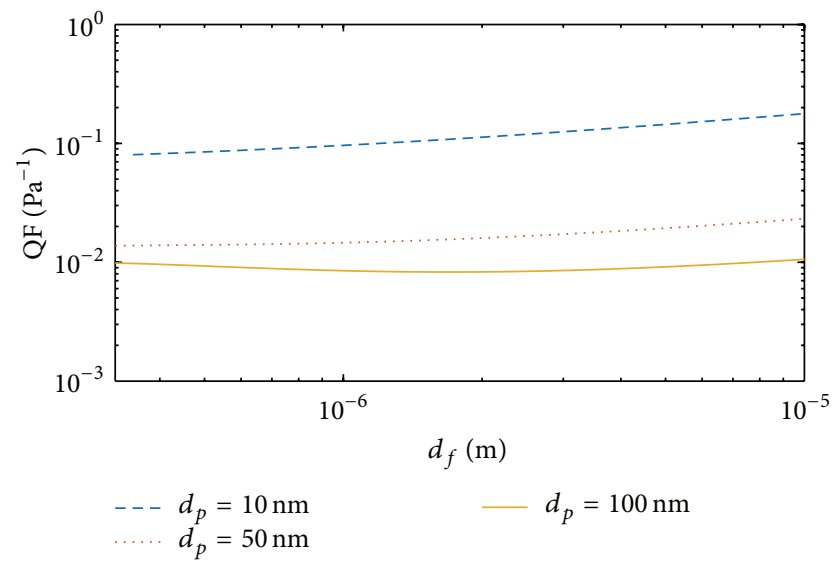

Figure 3: Effects of fiber diameter on the QF of a single-layer filter $(U=0.1 \mathrm{~m} / \mathrm{s}, c=0.05$, and $h=1 \mathrm{~mm})$.

the path of the air stream or deviate from the path and then compact fibers due to inertia. The concave curves in Figure 2 indicate that the values of QF vary with particle size under different filtration mechanisms, which is similar to those of filtration efficiency. For improvement of QF, therefore, it is essential to consider all three filtration mechanisms simultaneously.

Capture of particles of a given size is of great interest in specific filtration. In Figure 3, we investigate the effect of fiber diameter on the QF of a single-layer filter, by capturing nanoparticles with diameters $0.01 \mu \mathrm{m}, 0.05 \mu \mathrm{m}$, and $0.1 \mu \mathrm{m}$. The fiber diameter varies from $0.3 \mu \mathrm{m}$ to $10 \mu \mathrm{m}$, the filter thickness is $1 \mathrm{~mm}$, the face velocity is $0.1 \mathrm{~m} / \mathrm{s}$, and the solidity is 0.05 . We observe that the QF for particles of $0.01 \mu \mathrm{m}$ and $0.05 \mu \mathrm{m}$ increases monotonously with the increase in fiber diameter. The reason is that the pressure drop decreases more rapidly than the decrease in filtration efficiency with increasing fiber diameter. For nanoparticles of $0.1 \mu \mathrm{m}$, it is interesting to find the minimum QF from the concave line in Figure 3. This phenomenon reveals the complexity of the dependence of the QF on the structural parameters, as the decrease in the pressure drop can be outweighed by the decrease in filtration efficiency.

\section{QF and MQF of Dual-Layer Filters}

In particle filtration by a dual-layer filter, the gas streams are purified layer by layer. Thus, the total penetration of particles is the product of the penetration of the two layers:

$$
P_{t}=P_{1} P_{2}
$$

where $P_{t}, P_{1}$, and $P_{2}$ are the penetrations for the total filter, the first layer, and the second layer, which are given by $1-E_{t}$, $1-E_{1}$, and $1-E_{2}$, respectively. The subscript 1 represents the first layer (e.g., $c_{1}, h_{1}$, and $d_{f 1}$ ) and the subscript 2 indicates in the second layer (e.g., $c_{2}, h_{2}$, and $d_{f 2}$ ). The pressure drops are additive and the total pressure drop is the sum of the two local pressure drops:

$$
\Delta p_{t}=\Delta p_{1}+\Delta p_{2}
$$

where $\Delta p_{t}, \Delta p_{1}$, and $\Delta p_{2}$ are the pressure drops for the total filter, the first layer, and the second layer, respectively.

On the basis of (10) and (11), the QF for the dual-layer filter is given by

$$
\mathrm{QF}=\frac{-\ln \left(P_{1} P_{2}\right)}{\Delta p_{1}+\Delta p_{2}}=\frac{-\ln \left[\left(1-E_{1}\right)\left(1-E_{2}\right)\right]}{\Delta p_{1}+\Delta p_{2}} .
$$

The first layer is set as the control sample, so $P_{1}$ and $\Delta p_{1}$ are fixed. And the QF varies with the structural parameters of the second layer, namely, $c_{2}, h_{2}$, and $d_{f 2}$.

For polydisperse particles, we obtain the total penetration by considering the distribution of particle size:

$$
P=\int_{0}^{\infty} f\left(d_{p}\right) \exp \left[\frac{-4 c E_{t}\left(d_{p}\right) h}{\pi(1-c) d_{f}}\right] d\left(d_{p}\right)
$$

where $f\left(d_{p}\right)$ is the probability density function, which follows a lognormal distribution $[28,29]$ :

$$
f\left(d_{p}\right)=\frac{1}{d_{p} \sigma \sqrt{2 \pi}} e^{-\left[\ln \left(d_{p}\right)-\ln \left(\left\langle d_{p}\right\rangle\right)\right]^{2} / 2 \sigma^{2}},
$$

where $\left\langle d_{p}\right\rangle$ is the mean size of particles and $\sigma$ is the scale parameter.

As mentioned earlier, a good filter should have high filtration efficiency and flow velocity at a low energy consumption. As such, we propose a modified QF (MQF), which is an energy-based indicator of filter performance:

$$
\mathrm{MQF}=\frac{E U}{G},
$$

where $G$ is the energy cost of the filtration. $G$ is proportional to the pressure drop and the flow flux $Q$ : namely, $G=Q \Delta p$. Here, $Q$ is expressed as $Q=U S$, where $S$ is the cross-sectional 
area of the filter and is identical for both layers in a given filter system. Then, (15) is rewritten as

$$
\mathrm{MQF}=\frac{E}{S \Delta p}
$$

MQF is simply equivalent to the ratio of $E$ to $\Delta p$ for a given filter, while it is calculated by concerning the effects of energy cost and flow velocity.

The two layers have the same $U$ based on conservation of the flow flux and (9); namely,

$$
U=\frac{d_{f}}{4} \sqrt{\frac{G}{S c \mu h} \frac{\left\{-0.6 \ln (c)-0.74+c-0.25 c^{2}+2 \mathrm{Kn}\left[-0.6 \ln (c)-0.14+0.25 c^{2}\right]\right\}}{1+2 \mathrm{Kn}}} .
$$

Thus, $U$ is determined by $G$ for a given filter. Similarly, $G$ can be calculated as a function of $U$ if we fix $U$. In this study, we consider $G$ as the constraint for optimization of fibrous filters. Substituting (17) into (4), (8), (9), and (16), we have the MQF as follows:

$$
\mathrm{MQF}=\frac{1-P_{1} P_{2}}{S\left(\Delta p_{1}+\Delta p_{2}\right)}=\frac{1-P_{1} P_{2}}{S\left(\Delta p_{1}+\Delta p_{2}\right)},
$$

which is a function of $G$.

\section{Results and Discussion}

To find the optimal filtration performance, we focus on investigating the QF for a dual-layer filter with the first layer fixed while the second layer varied (Figure 1). The models we employ in this paper, including (4), (7), and (8) for filtration efficiency of single-layer or dual-layer fibrous filters and (9) for pressure drop of fibrous filters, have been well verified by experimental results $[5,18]$. The structural parameters of three types of the first, fixed layers are summarized in Table 2. The second layers have different solidity, thickness, and fiber diameter, and the face velocity is set as $U=0.1 \mathrm{~m} / \mathrm{s}$. We focus mainly on the filtration of particles of a specific size, but we still examine the effect of the polydispersity degree of the particles on the QF. Since the filtration of nanoparticles is less understood [1] and the MPPS is often around $100 \mathrm{~nm}$ $[3,17]$, we focus on the QF of nanoparticles with $d_{p}=$ $10 \mathrm{~nm}$ and $d_{p}=100 \mathrm{~nm}$. It is noted that QF is not the only criterion by which the filter quality is measured [17]; the evaluation depends on target requirements and specific operating conditions. Thus, we also explore the MQF by considering the influence of energy cost and flow velocity.

For the filter of Type 1, variations of QF against $c_{2}$ and $d_{f 2}$ at $U=0.1 \mathrm{~m} / \mathrm{s}, d_{p}=10 \mathrm{~nm}, h_{1}=3 \mathrm{~mm}$, and $h_{2}=1,3,9 \mathrm{~mm}$ are shown in Figure 4. The concave curves in Figure 4(a) indicate the optimal filters with the highest QF against $c_{2}$ when $c_{1}$ is equal to 0.1 . The maximum QF results vary with the corresponding values of $c_{2}$, which are around $0.04,0.05$, and 0.06 for $h_{2}=1,3,9 \mathrm{~mm}$, respectively. In addition, the maximum QF increases with the increase in $h_{2}$. It is noted that the three filters have the same QF when $c_{2}=c_{1}=0.1$ at the crossover of curves, and the dual-layer filter becomes a singlelayer filter with its QF independent of thickness. When $c_{2}>$ 0.1 , the QF values decrease dramatically with the increase in $c_{2}$, revealing the inefficiency of the filters in capturing the particles of $d_{p}=10 \mathrm{~nm}$. This finding is consistent with the experimental results that the highest QF is found within five different values of $c_{2}$ for a nanofiber-microfiber duallayer filter [18]. For the filtration of the particles with $d_{p}=$ $100 \mathrm{~nm}$, Figure 4(b) shows a similar trend of the QF against $c_{2}$. However, the maximum QF values for $d_{p}=100 \mathrm{~nm}$ are much smaller than those for $d_{p}=10 \mathrm{~nm}$. Hence, the duallayer filters with $d_{f 1}=d_{f 2}=10 \mu \mathrm{m}$ have a better filtration performance for fine particles, which is similar to that of the single-layer filter. Figures $4(\mathrm{c})$ and $4(\mathrm{~d})$ show the dependence of QF on $d_{f 2}$ for $d_{p}=10 \mathrm{~nm}$ and $d_{p}=100 \mathrm{~nm}$, respectively. Here, we have $c_{2}=c_{1}=0.1, h_{1}=3 \mathrm{~mm}$, and $h_{2}=1,3,9 \mathrm{~mm}$. In Figure $4(\mathrm{c})$, the maximum $\mathrm{QF}$ results are found against $d_{f 2}$, with the corresponding values of $d_{f 2}$ equal to $1.5 \mu \mathrm{m}$, $2 \mu \mathrm{m}$, and $2.5 \mu \mathrm{m}$ for $h_{2}=1,3,9 \mathrm{~mm}$, respectively. When $d_{f 2}$ is smaller than $d_{f 1}=10 \mu \mathrm{m}$, the QF decreases considerably with the decrease in $d_{f 2}$. Therefore, the addition of nanofibers onto the substrate or the first layer might not be reasonable in this case, although the filtration efficiency of nanofibers is much higher. In Figure 4(d), the maximum QF values for $d_{p}=100 \mathrm{~nm}$ are much lower than those for $d_{p}=10 \mathrm{~nm}$ in Figure 4(c). The maximum QFs observed in Figures 4(c) and 4(d) look slightly higher than the QF of a single-layer filter, but selection of the optimized second layer avoids the significant decline in QF caused by using inappropriate fibers. Figure 4 also demonstrates that two layers with close fiber diameters or solidity have higher QF than those with a very broad difference in fiber size or solidity.

Figures 5 and 6 illustrate the dependence of the QF on the structural parameters for the dual-layer filters Type 2 and Type 3, respectively. As for Type 1, their maximum QF results are found at different thickness ratios, with the corresponding values of $c_{2}$ slightly smaller than $c_{1}$ while the corresponding values of $d_{f 2}$ are moderately larger than $d_{f 1}$.

In Figure 7 we study the effects of face velocity on the $\mathrm{QF}$ of the dual-layer filter against $d_{f_{2}}$ at $d_{p}=100 \mathrm{~nm}, h_{1}=$ $h_{2}=3 \mathrm{~mm}, d_{f 1}=10 \mu \mathrm{m}$, and $c_{1}=c_{2}=0.1$. The maximum QF values are visible and they increase with the decrease in $U$. It is feasible to argue that a smaller face velocity ensures more adequate contact between fibers and particles, yielding a higher QF. However, a very small $U$ can slow down the filtration processes even though the QF is satisfactory. Hence, we optimize the filter on the basis of the QF in the desired range of face velocity.

In Figure 8 we compare the QF values between monodisperse and polydisperse particles with the same mean particle 


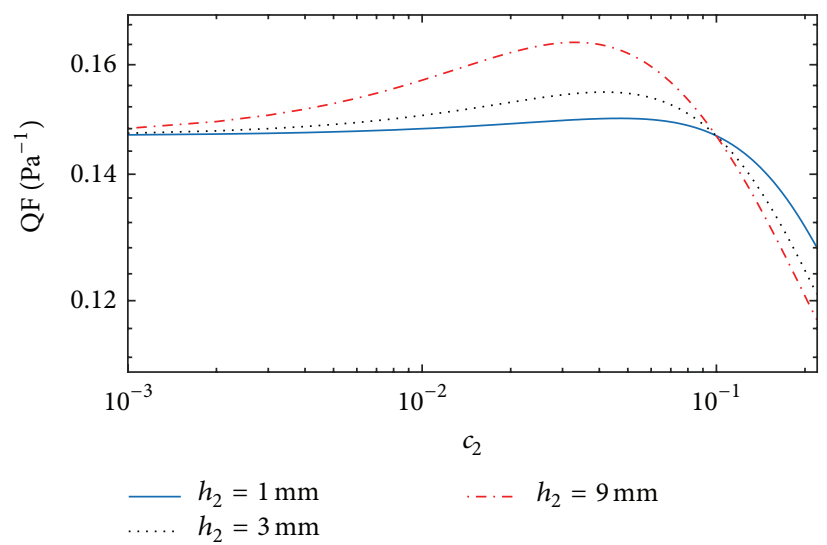

(a)

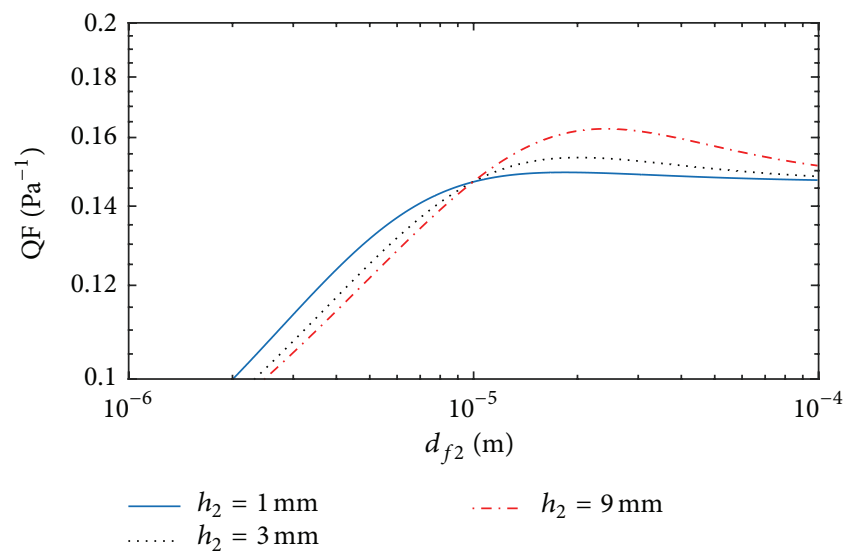

(c)

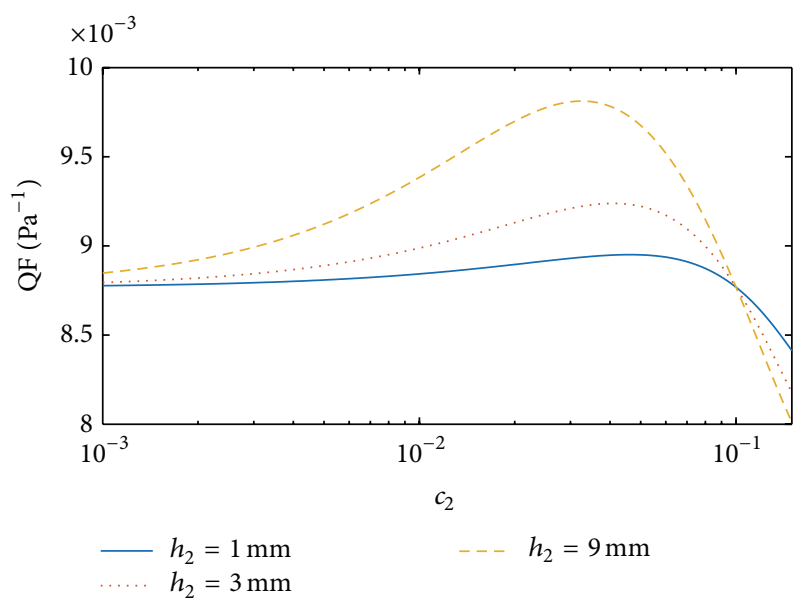

(b)

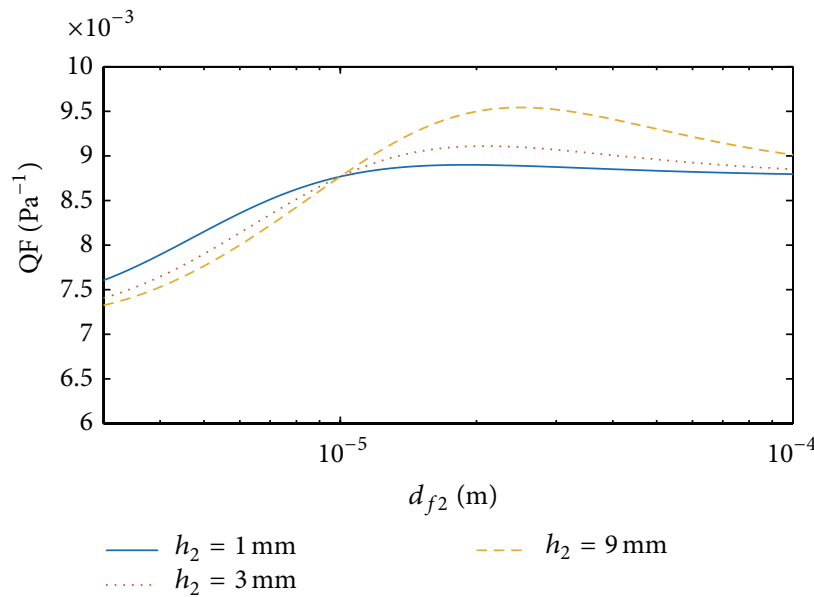

(d)

FIGURE 4: Effects of solidity of the second layer on the QF of the dual-layer filter with $d_{f 1}=d_{f 2}=10 \mu \mathrm{m}$ and $c_{1}=0.1$, for particles with diameters (a) $d_{p}=10 \mathrm{~nm}$ and (b) $d_{p}=100 \mathrm{~nm}$, and effects of fiber diameter of the second layer on the QF at $c_{1}=c_{2}=0.1$ and $d_{f 1}=10 \mu \mathrm{m}$, for particles with diameters (c) $d_{p}=10 \mathrm{~nm}$ and (d) $d_{p}=100 \mathrm{~nm}\left(U=0.1 \mathrm{~m} / \mathrm{s}, h_{1}=3 \mathrm{~mm}\right.$, and $\left.h_{2}=1,3,9 \mathrm{~mm}\right)$.

TABLE 2: Structural parameters of the first layer in a dual-layer filter for filtration of particles of $d_{p}=10 \mathrm{~nm}$ and $d_{p}=100 \mathrm{~nm}$ at $U=$ $0.1 \mathrm{~m} / \mathrm{s}$.

\begin{tabular}{lccc}
\hline Type & $c_{1}$ & $d_{f 1}$ & $h_{1}$ \\
\hline 1 & 0.1 & $10 \mu \mathrm{m}$ & $3 \mathrm{~mm}$ \\
2 & 0.05 & $2 \mu \mathrm{m}$ & $1 \mathrm{~mm}$ \\
3 & 0.01 & $0.4 \mu \mathrm{m}$ & $0.2 \mathrm{~mm}$ \\
\hline
\end{tabular}

size. The solidity of the second layer $c_{2}$ varies in Figure 8(a), with $\left\langle d_{p}\right\rangle=100 \mathrm{~nm}, c_{1}=0.1, h_{1}=3 \mathrm{~mm}, h_{2}=9 \mathrm{~mm}, d_{f 1}=$ $d_{f 2}=10 \mu \mathrm{m}$, and $U=0.1 \mathrm{~m} / \mathrm{s}$. Figure $8(\mathrm{~b})$ demonstrates the dependence of QF on the fiber diameter of the second layer $d_{f 2}$, with $\left\langle d_{p}\right\rangle=10 \mathrm{~nm}, c_{1}=c_{2}=0.01, h_{1}=h_{2}=0.2 \mathrm{~mm}$, $d_{f 1}=0.4 \mu \mathrm{m}$, and $U=0.1 \mathrm{~m} / \mathrm{s}$. The particle size follows a lognormal distribution with different scale parameters $\sigma$. For the monodisperse particles, the maximum QF results are found for polydisperse particles. With increasing $\sigma$ and the narrowing distribution of particle size, the maximum
QF values increase as $d_{f 2}$ at $c_{1}=c_{2}$ but decrease as $c_{2}$ at $d_{f 1}=d_{f 2}$. It is demonstrated that the value of QF of the dual-layer filter against polydisperse particles is increased by around $10 \%$ than that of the fixed single first layer, which is equivalent to the two-layer fibrous filter with the solidity of the second layer extremely small. When $\sigma$ is very small, the QF curves of for polydisperse particles nearly overlap with those of monodisperse particles, as expected. It is interesting to note that the optimal structural parameters accounting for the maximum QF are close between monodisperse and the polydisperse particles.

The maximum MQF values of the dual-layer filter against the solidity, the fiber diameter, and the thickness of the second layer are shown in Figures 9(a), 9(b), and 9(c), respectively. We set $G=3.28 \mathrm{~W}$ and $S=0.005 \mathrm{~m}^{2}$ for a fibrous filter in a commercial respirator at $U=0.1 \mathrm{~m} / \mathrm{s}$. The values of $G$ and $S$ are determined by the target filters and operating conditions. In Figure 9(a), we have $c_{1}=0.01, d_{f 1}=1 \mu \mathrm{m}, h_{1}=h_{2}=$ $0.2 \mathrm{~mm}$, and $d_{p}=100 \mathrm{~nm}$, and the maximum MQF values of the dual-layer filter are found against $c_{2}$ at $d_{f 2}=0.5,1,2 \mu \mathrm{m}$. 


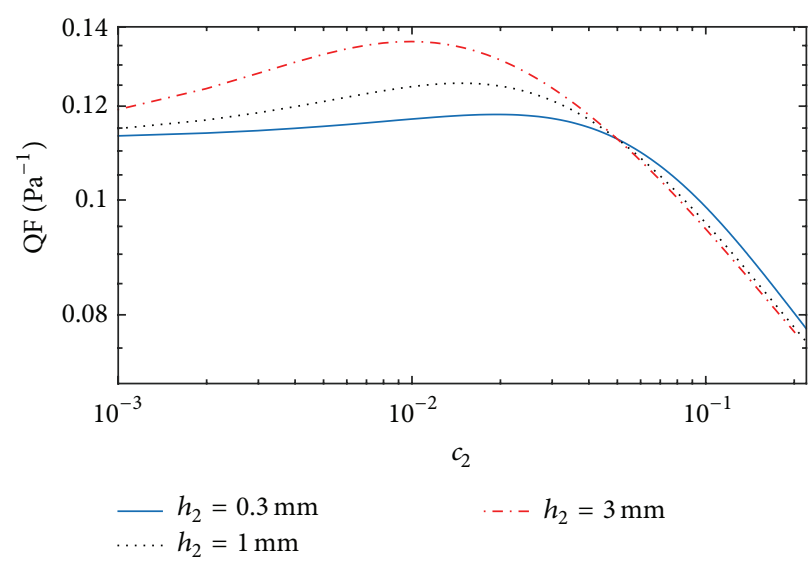

(a)

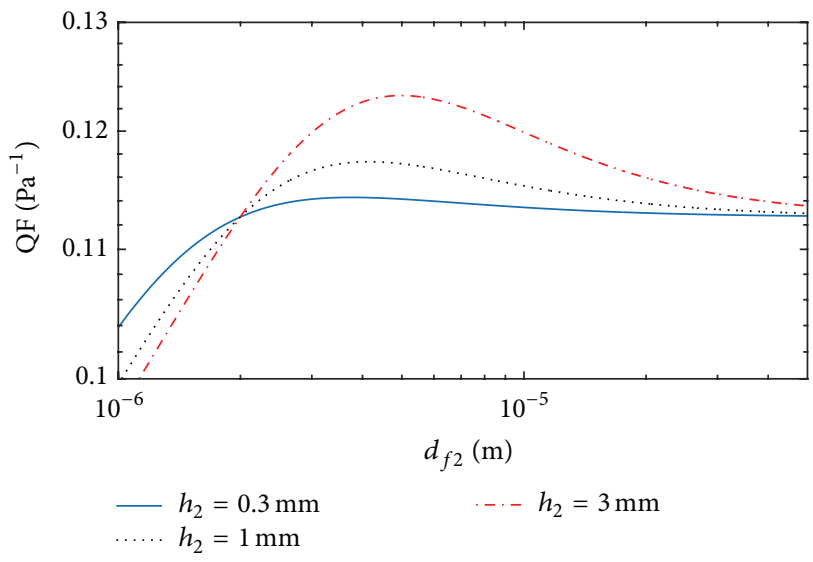

(c)

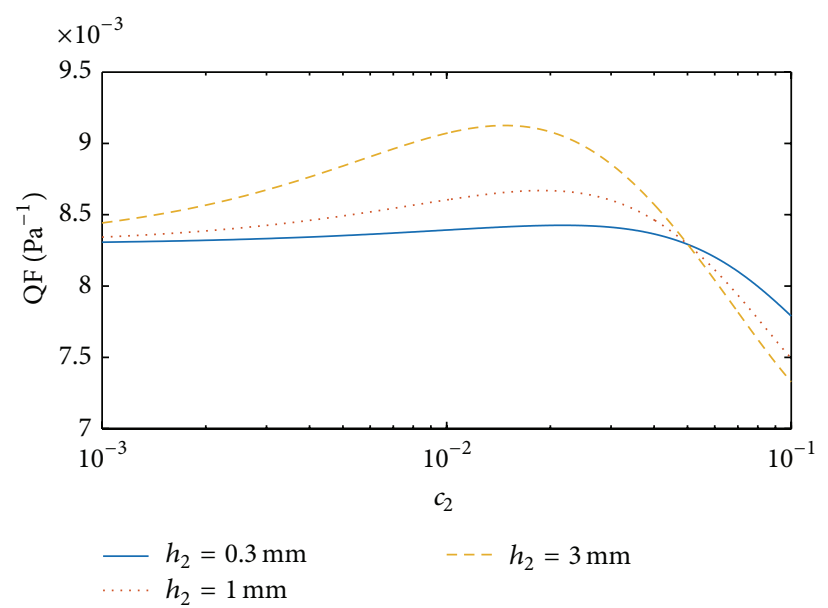

(b)

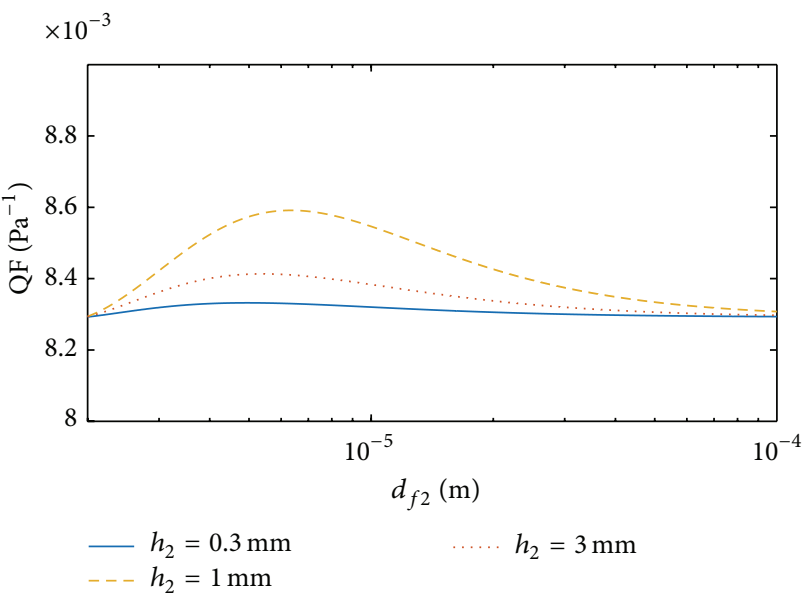

(d)

FIGURE 5: Effects of solidity of the second layer on the QF of the dual-layer filter with $d_{f 1}=d_{f 2}=2 \mu \mathrm{m}$ and $c_{1}=0.05$, for particles with diameters (a) $d_{p}=10 \mathrm{~nm}$ and (b) $d_{p}=100 \mathrm{~nm}$, and effects of fiber diameter of the second layer on the QF of the dual-layer filter with $c_{1}=c_{2}=0.05$ and $d_{f 1}=2 \mu \mathrm{m}$, for particles with diameters (c) $d_{p}=10 \mathrm{~nm}$ and $(\mathrm{d}) d_{p}=100 \mathrm{~nm}\left(U=0.1 \mathrm{~m} / \mathrm{s}, h_{1}=1 \mathrm{~mm}\right.$, and $h_{2}=0.3,1$, $3 \mathrm{~mm})$.

The maximum MQF results decrease with increases in $c_{2}$ and the corresponding values of $c_{2}$ vary considerably for different $c_{1}$, which is unlike the QF responses. The optimal MQF of the dual-layer filter is found to be over twice of that of the fixed single first layer. In Figure 9(b), the maximum values of MQF are found against $d_{f 2}$ at $c_{2}=0.005,0.01,0.02$, and they decline with increasing $d_{f 2}$. The corresponding values of $d_{f 2}$ for the maximum MQF are smaller than $d_{f 1}$, which is also unlike that for QF. Finally, in Figure 9(c) the dependence of MQF on $h_{2}$ is investigated at $c_{2}=0.005,0.01,0.02$ with $d_{f 2}=1 \mu \mathrm{m}$ and $d_{f 2}=0.5,1,2 \mu \mathrm{m}$ with $c_{1}=0.01$. The maximum MQF increases with increasing $d_{f 2}$ but decreases with the increase in $c_{2}$. Among the different cases, the values of $h_{2}$ corresponding to the maximum QF vary considerably, indicating the significance of choosing the appropriate thickness of the dual-layer filter to improve filtration performance. To summarize, the requisite conditions for the optimal QF are based on the fact that the total filtration efficiency has a slower decrease rate before the threshold of structural parameters is reached but then a faster decrease rate than the total pressure drop at the given energy cost.

\section{Conclusion}

In this study, the filtration performance of the dual-layer fibrous filter is theoretically studied based on closed-form models. We find the best filter performance in terms of QF for the nanoparticles with a specific size such as the MPPS, the mean particle size, or the highest proportion of a given particle size. The findings are summarized as follows:

(i) The maximum QF for the capture of monodisperse and polydisperse nanoparticles is found against the variation of solidity, thickness, and fiber diameter of the second layer, when the first layer is fixed.

(ii) Under a given energy cost, the optimal filters are found with the highest MQF against variations of 


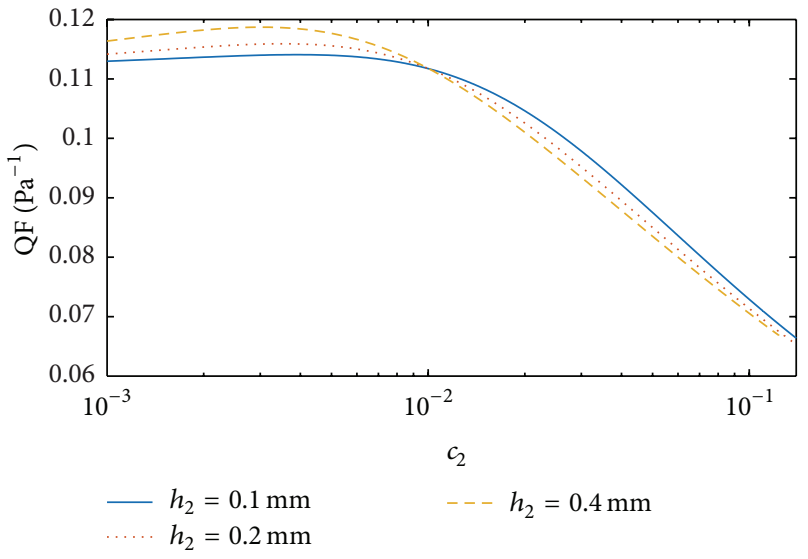

(a)

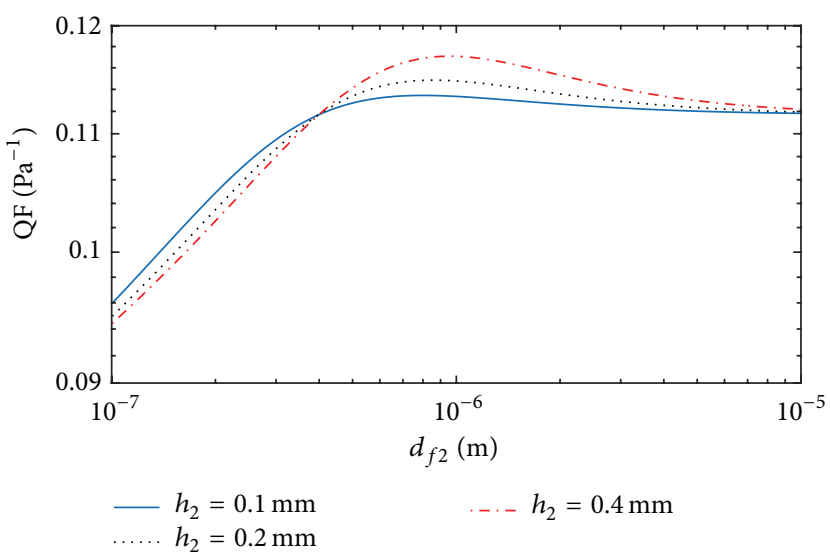

(c)

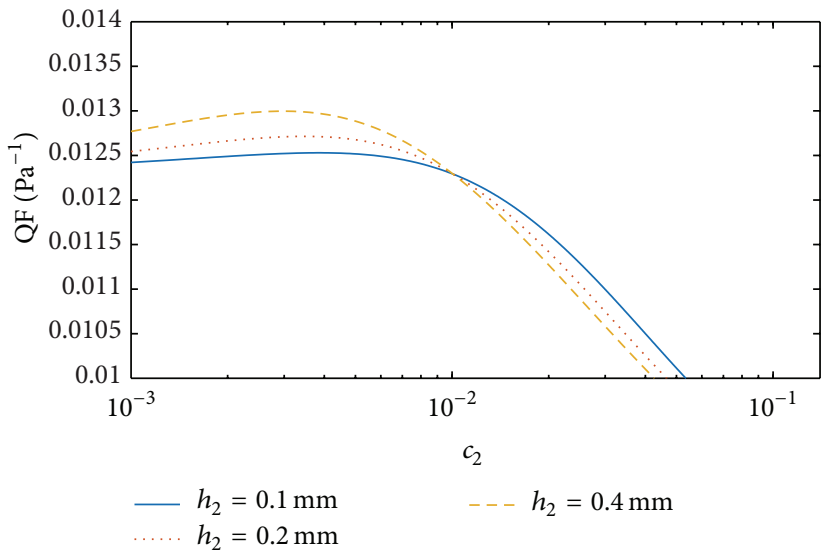

(b)

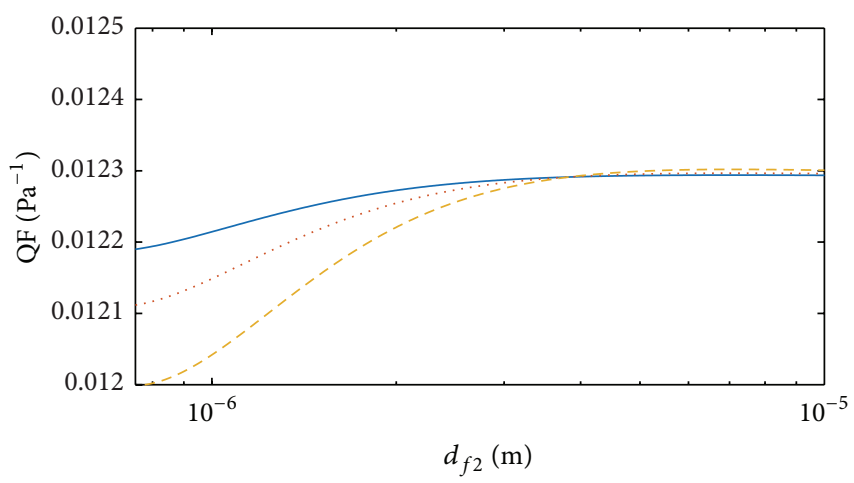

$$
\begin{aligned}
-h_{1} & =0.1 \mathrm{~mm} \\
\ldots . . . h_{1} & =0.2 \mathrm{~mm}
\end{aligned}
$$

(d)

FIGURE 6: Effects of solidity of the second layer on the QF of the dual-layer filter with $d_{f 1}=d_{f 2}=0.4 \mu \mathrm{m}$ and $c_{1}=0.01$, for particles with diameters (a) $d_{p}=10 \mathrm{~nm}$ and (b) $d_{p}=100 \mathrm{~nm}$, and effects of fiber diameter of the second layer on the QF of the dual-layer filter with $c_{1}=c_{2}=0.01$ and $d_{f 1}=0.4 \mu \mathrm{m}$, for particles with diameters (c) $d_{p}=10 \mathrm{~nm}$ and (d) $d_{p}=100 \mathrm{~nm}\left(U=0.1 \mathrm{~m} / \mathrm{s}, h_{1}=0.2 \mathrm{~mm}\right.$, and $h_{2}=0.1$, $0.2,0.4 \mathrm{~mm}$ ).

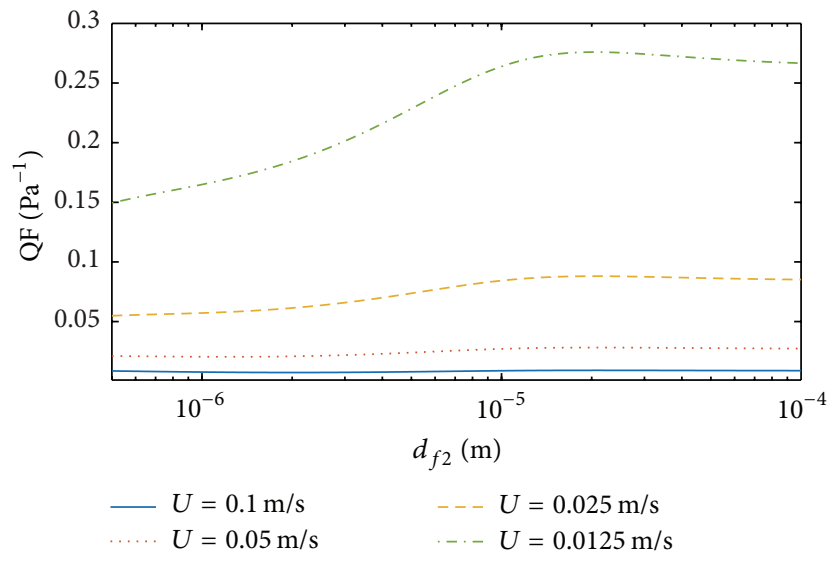

FIGURE 7: Effects of face velocity on the QF of a dual-layer filter with varying $d_{f 2}\left(d_{p}=100 \mathrm{~nm}, h_{1}=h_{2}=3 \mathrm{~mm}, d_{f 1}=10 \mu \mathrm{m}\right.$, and $\left.c_{1}=c_{2}=0.1\right)$. 


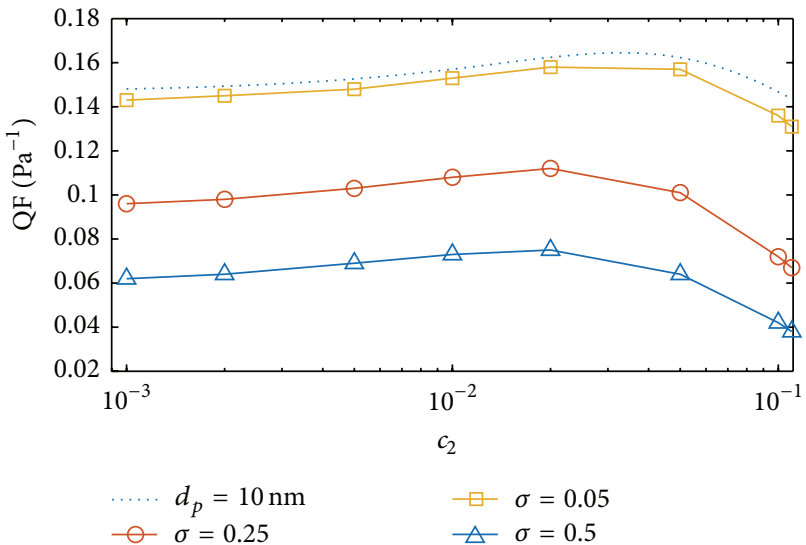

(a)

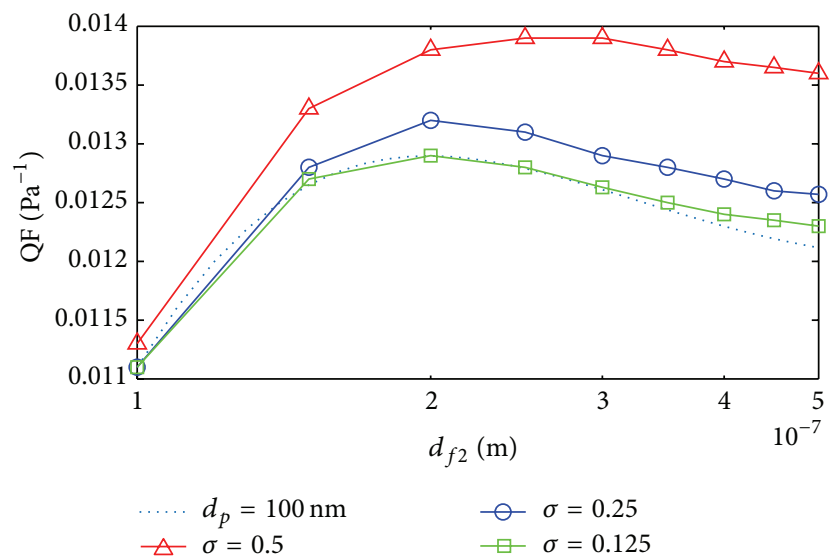

(b)

FIGURE 8: Comparison of optimal QF between monodisperse and polydisperse particles against (a) the solidity of the second layer at $\left\langle d_{p}\right\rangle=$ $100 \mathrm{~nm}, c_{1}=0.1, h_{1}=3 \mathrm{~mm}, h_{2}=9 \mathrm{~mm}, d_{f 1}=d_{f 2}=10 \mu \mathrm{m}$, and $U=0.1 \mathrm{~m} / \mathrm{s}$; (b) the fiber diameter of the second layer at $\left\langle d_{p}\right\rangle=$ $10 \mathrm{~nm}, c_{1}=c_{2}=0.01, h_{1}=h_{2}=0.2 \mathrm{~mm}, d_{f 1}=0.4 \mu \mathrm{m}$, and $U=0.1 \mathrm{~m} / \mathrm{s}$.

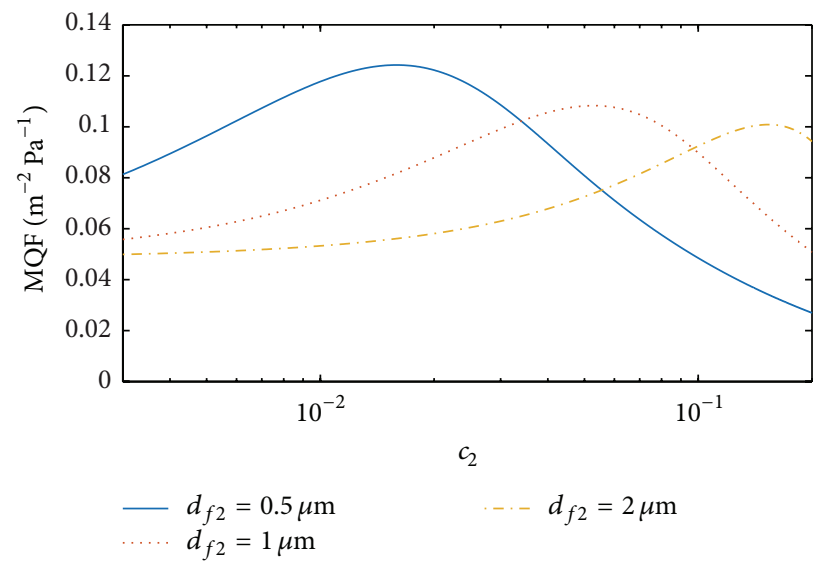

(a)

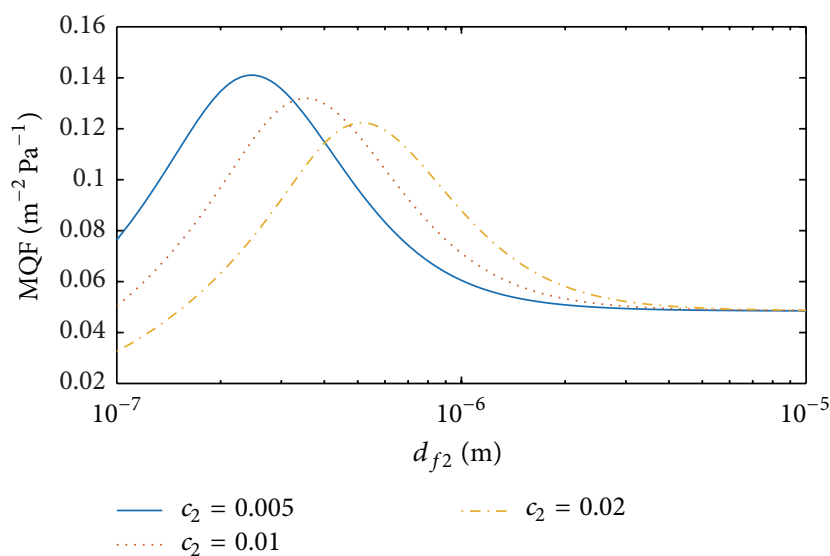

(b)

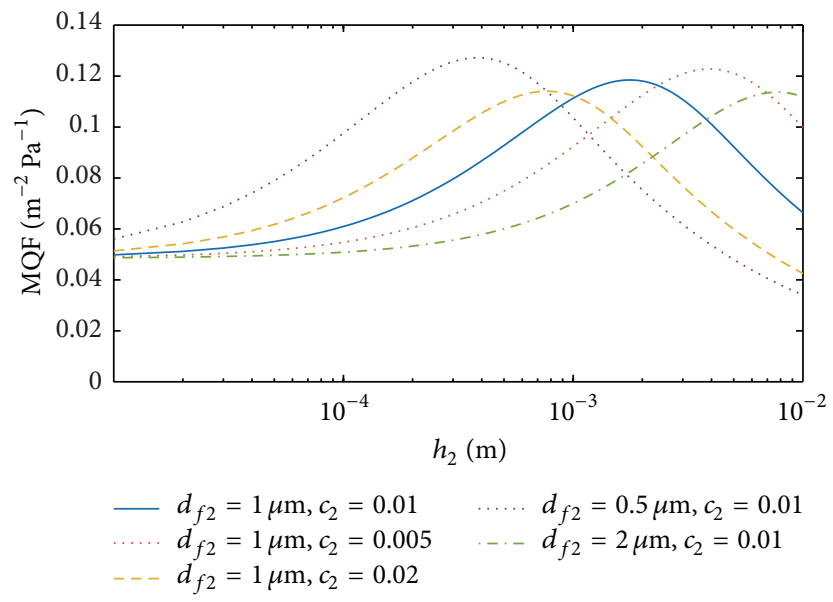

(c)

FIGURE 9: Maximum values of MQF of the dual-layer filter against (a) solidity $\left(h_{1}=h_{2}=0.2 \mathrm{~mm}, c_{1}=0.01, d_{f 1}=1 \mu \mathrm{m}\right.$, and $d_{f 2}=0.5$, $1,2 \mu \mathrm{m})$, (b) fiber diameter $\left(h_{1}=h_{2}=0.2 \mathrm{~mm}, d_{f 1}=1 \mu \mathrm{m}, c_{1}=0.01\right.$, and $\left.c_{2}=0.005,0.01,0.02\right)$, and (c) thickness of the second layer, at $c_{1}=0.01, d_{f 1}=1 \mu \mathrm{m}, d_{p}=100 \mathrm{~nm}, G=3.28 \mathrm{~W}, S=0.005 \mathrm{~m}^{2}$, and $U=0.1 \mathrm{~m} / \mathrm{s}$. 
solidity, thickness, and fiber diameter of the second layer when the first layer is fixed.

(iii) The optimal QF of the dual-layer filter is enhanced by around $10 \%$ than that of the fixed first layer, while the maximum MQF can be increased to be over twice in certain cases.

(iv) The optimal structural parameters accounting for the maximum QF vary with face velocity and particle size distribution.

This work provides a quick tool to design and optimize fibrous filters with better filtration performance of nanoparticles. To avoid expensive computation, current studies are limited to the filter fibers with constant diameter and circular shape and they also assume negligible clogging of particles. The above concerns will be addressed in future work with the assistance of the Computational Fluid Dynamics (CFD) technique. As well, optimization of the fiber surface roughness, the sizes of the nanorods grown on the fiber wall, and the clogging distribution in different filter layers will also be explored to prompt the best filtration performance.

\section{Conflict of Interests}

The authors declare that there is no conflict of interests regarding the publication of this paper.

\section{Acknowledgment}

The coauthors Jintu Fan and Xiaoming Qian acknowledge the funding support of Tianjin City Applied Foundation \& Emerging Technology Research Program (Grant no. 15JCZDJC38500).

\section{References}

[1] C.-S. Wang and Y. Otani, "Removal of nanoparticles from gas streams by fibrous filters: a review," Industrial \& Engineering Chemistry Research, vol. 52, no. 1, pp. 5-17, 2013.

[2] R. C. Brown, Air Filtration: An Integrated Approach to the Theory and Applications of Fibrous Filters, Pergamon Press, Oxford, UK, 1993.

[3] A. Podgórski, A. Bałazy, and L. Gradoń, "Application of nanofibers to improve the filtration efficiency of the most penetrating aerosol particles in fibrous filters," Chemical Engineering Science, vol. 61, no. 20, pp. 6804-6815, 2006.

[4] D. Shou, J. Fan, and F. Ding, "Hydraulic permeability of fibrous porous media," International Journal of Heat and Mass Transfer, vol. 54, no. 17-18, pp. 4009-4018, 2011.

[5] D. Shou, L. Ye, and J. Fan, "Gas transport properties of electrospun polymer nanofibers," Polymer, vol. 55, no. 14, pp. 3149-3155, 2014.

[6] S. Dhaniyala and B. Y. H. Liu, "Theoretical modeling of filtration by nonuniform fibrous filters," Aerosol Science and Technology, vol. 34, no. 2, pp. 170-178, 2001.

[7] S. Dhaniyala and B. Y. H. Liu, "An asymmetrical, threedimensional model for fibrous filters," Aerosol Science and Technology, vol. 30, no. 4, pp. 333-348, 1999.
[8] D. Shou, J. Fan, H. Zhang, X. Qian, and L. Ye, "Filtration efficiency of non-uniform fibrous filters," Aerosol Science and Technology, vol. 49, no. 10, pp. 912-919, 2015.

[9] K. W. Lee and B. Y. H. Liu, "Theoretical-study of aerosol filtration by fibrous filters," Aerosol Science and Technology, vol. 1, no. 2, pp. 147-161, 1982.

[10] W. W.-F. Leung, C.-H. Hung, and P.-T. Yuen, "Effect of face velocity, nanofiber packing density and thickness on filtration performance of filters with nanofibers coated on a substrate," Separation and Purification Technology, vol. 71, no. 1, pp. 30-37, 2010.

[11] X.-H. Qin and S.-Y. Wang, "Filtration properties of electrospinning nanofibers," Journal of Applied Polymer Science, vol. 102, no. 2, pp. 1285-1290, 2006.

[12] X.-H. Qin and S.-Y. Wang, "Electrospun nanofibers from crosslinked poly(vinyl alcohol) and its filtration efficiency," Journal of Applied Polymer Science, vol. 109, no. 2, pp. 951-956, 2008.

[13] H. Schreuder-Gibson, P. Gibson, K. Senecal et al., "Protective textile materials based on electrospun nanofibers," Journal of Advanced Materials, vol. 34, no. 3, pp. 44-55, 2002.

[14] P. Gibson, H. Schreuder-Gibson, and D. Rivin, "Transport properties of porous membranes based on electrospun nanofibers," Colloids and Surfaces A: Physicochemical and Engineering Aspects, vol. 187-188, pp. 469-481, 2001.

[15] J. Matulevicius, L. Kliucininkas, D. Martuzevicius, E. Krugly, M. Tichonovas, and J. Baltrusaitis, "Design and characterization of electrospun polyamide nanofiber media for air filtration applications," Journal of Nanomaterials, vol. 2014, Article ID 859656, 13 pages, 2014.

[16] M. Faccini, C. Vaquero, and D. Amantia, "Development of protective clothing against nanoparticle based on electrospun nanofibers," Journal of Nanomaterials, vol. 2012, Article ID 892894, 9 pages, 2012

[17] J. Wang, S. C. Kim, and D. Y. H. Pui, "Figure of merit of composite filters with micrometer and nanometer fibers," Aerosol Science and Technology, vol. 42, no. 9, pp. 722-728, 2008.

[18] J. Wang, S. C. Kim, and D. Y. H. Pui, "Investigation of the figure of merit for filters with a single nanofiber layer on a substrate," Journal of Aerosol Science, vol. 39, no. 4, pp. 323-334, 2008.

[19] Q. Zhang, J. Welch, H. Park, C.-Y. Wu, W. Sigmund, and J. C. M. Marijnissen, "Improvement in nanofiber filtration by multiple thin layers of nanofiber mats," Journal of Aerosol Science, vol. 41, no. 2, pp. 230-236, 2010.

[20] K. M. Yun, A. B. Suryamas, F. Iskandar, L. Bao, H. Niinuma, and K. Okuyama, "Morphology optimization of polymer nanofiber for applications in aerosol particle filtration," Separation and Purification Technology, vol. 75, no. 3, pp. 340-345, 2010.

[21] N. Wang, Y. S. Si, N. Wang et al., "Multilevel structured polyacrylonitrile/silica nanofibrous membranes for high-performance air filtration," Separation and Purification Technology, vol. 126, pp. 44-51, 2014.

[22] G. Viswanathan, D. B. Kane, and P. J. Lipowicz, "High efficiency fine particulate filtration using carbon nanotube coatings," Advanced Materials, vol. 16, no. 22, pp. 2045-2049, 2004.

[23] P. Li, Y. Zong, Y. Zhang et al., "In situ fabrication of depthtype hierarchical CNT/quartz fiber filters for high efficiency filtration of sub-micron aerosols and high water repellency," Nanoscale, vol. 5, no. 8, pp. 3367-3372, 2013.

[24] P. Li, C. Wang, Y. Zhang, and F. Wei, "Air filtration in the free molecular flow regime: a review of high-efficiency particulate 
air filters based on carbon nanotubes," Small, vol. 10, no. 22, pp. 4553-4561, 2014.

[25] A. Podgórski, On the Transport, Deposition and Filtration of Aerosol Particles: Selected Problems, Publishing House of the Warsaw University of Technology, Warsaw, Poland, 2002.

[26] W. W.-F. Leung, C.-H. Hung, and P.-T. Yuen, "Experimental investigation on continuous filtration of sub-micron aerosol by filter composed of dual-layers including a nanofiber layer," Aerosol Science and Technology, vol. 43, no. 12, pp. 1174-1183, 2009.

[27] J. Pich, "The filtration theory of highly dispersed aerosols," Staub, Reinhaltung der Luft, vol. 5, pp. 16-23, 1965.

[28] S. B. Kwon, H. T. Kim, and K. W. Lee, "Analytic solutions to diffusional deposition of polydisperse aerosols in fibrous filters," Aerosol Science and Technology, vol. 36, no. 6, pp. 742-747, 2002.

[29] C. B. Song and H. S. Park, "Analytic solutions for filtration of polydisperse aerosols in fibrous filter," Powder Technology, vol. 170, no. 2, pp. 64-70, 2006. 

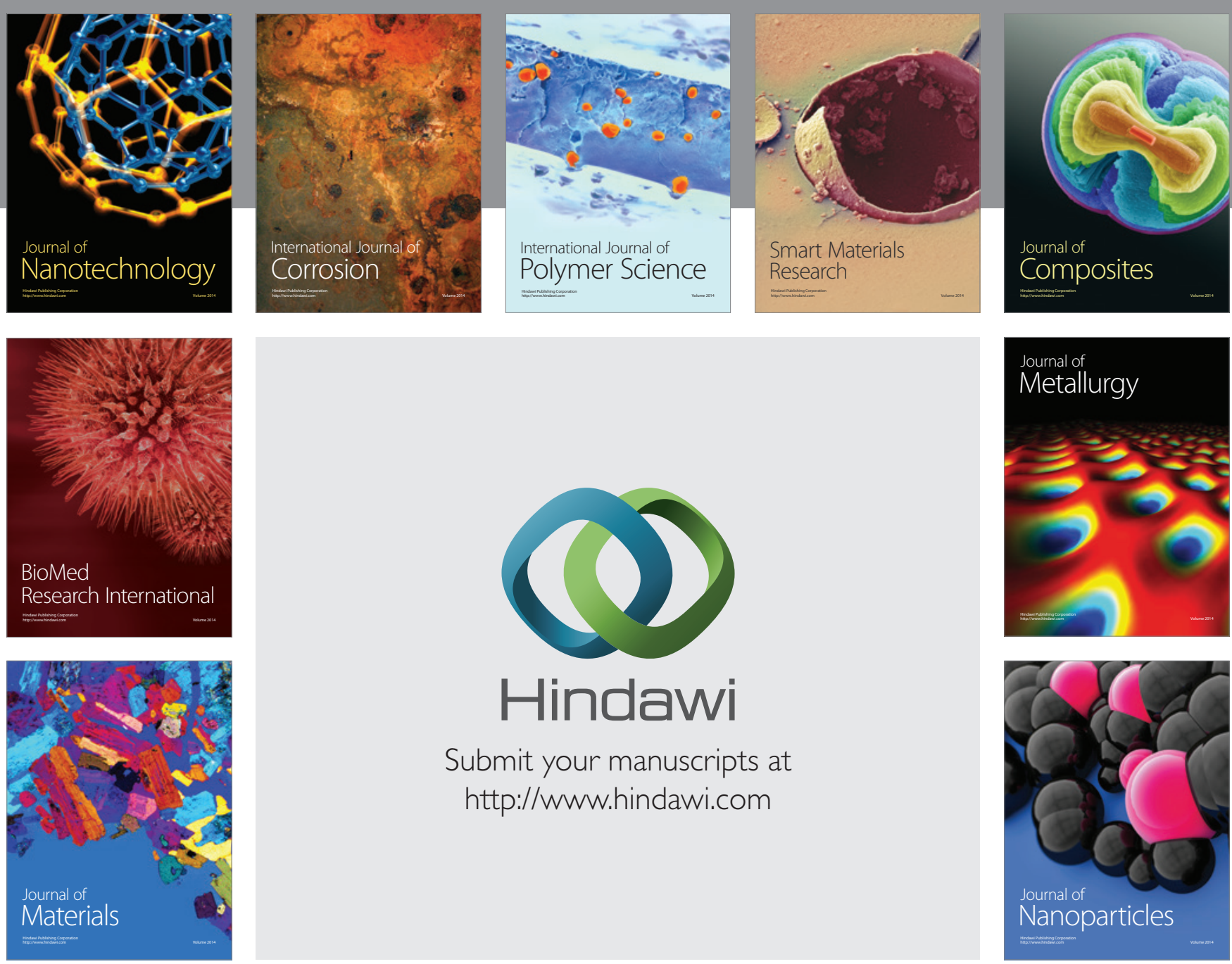

Submit your manuscripts at http://www.hindawi.com
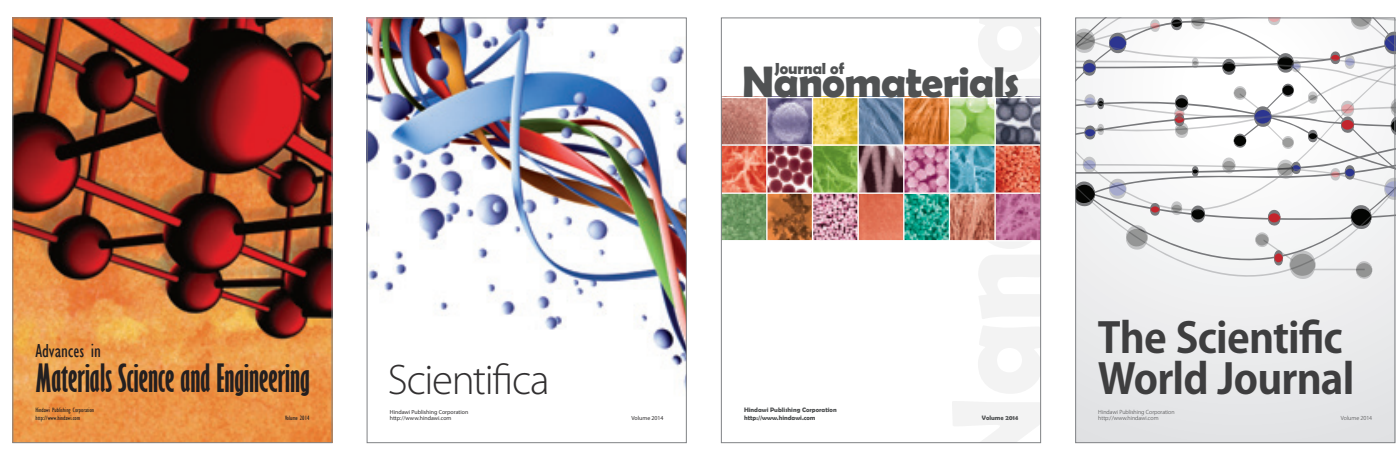

\section{The Scientific World Journal}
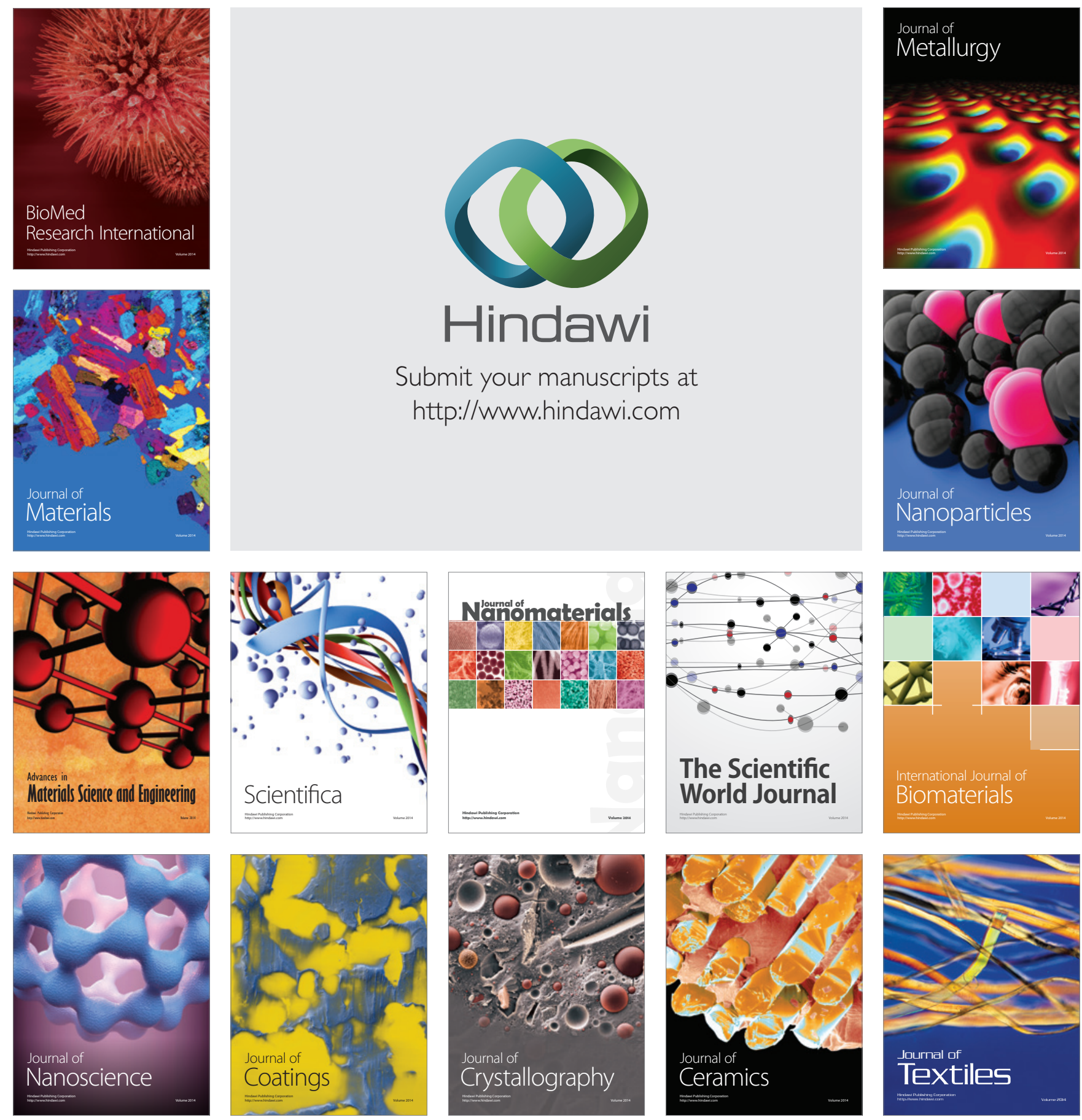